\title{
'El regreso de D. Quijote' de Chesterton. Tradición y utopía
}

\author{
Pilar Vega RodrígueZ*
}

1. A través de Deleuze y Guattari hemos aprendido a perder el miedo a ocuparnos de autores que la academia ha ubicado fuera del canon, y de poetas y prosistas como Borges a tener la desvergüenza de tratar los géneros y las creaciones literarias sin más recomendaciones que nuestra inclinación personal. Gilbert Keith Chesterton es uno de esos escritores marginados de la erudición crítica, no tanto por razones intrínsecas a su obra, extensísima y profundamente original ${ }^{1}$, como por su conocido itinerario intelectual (que desemboca tras una larga reflexión en el catolicismo) así como por su adscripción casi mecánica al género de la literatura de humor o cómica. Autor de un centenar de libros, liberal y antiimperialista, partidario de la causa böer en la guerra de África y a favor de la independencia de los irlandeses, ensayista agudo y polemista invencible, jovial y bienhumorado, no debería hacerse necesario recomendar al autor. Y sin embargo, la novela de que voy a ocuparme es buen ejemplo de este prejuicio. Se trata de El regreso de D. Quijote, (The Return of D. Quixote) publicada por entregas en el G.K's Weekly de diciembre de 1925 a noviembre de 1926 y editada en forma de libro un año después. En España la sacó Cosmópolis², según cita Palau (Manual del librero hispanoamericano) en ese mismo año de 1927, aunque la edición carece de indicaciones

\footnotetext{
* Universidad Complutense de Madrid.

1. Novelas, poemas, crítica, obras de teatro, dos centenares de cuentos y unos mil artículos de prensa.

2. Probable continuación de la revista del mismo nombre fundada en 1883 y que tan importante papel desempeñó en nuestro país como portavoz del modernismo europeo y americano. La revista fundada por Gómez Carrillo aparece vigente entre 1919 y 1922. Pese a sus previsiones generalistas publicó abundantes poemas y noticias de la vanguardia, en concreto, varios de los artículos que después
} 
cronológicas y posiblemente podría retrasarse un par de años más de tener en cuenta el anuncio publicitario de la contraportada. Fue traducida del inglés por el periodista peruano César Falcón a la sazón corresponsal del diario El Sol en Londres. César Falcón mantenía desde su juventud una relación estrecha con los círculos del liberalismo radical y el socialismo y a su regreso de Inglaterra, en 1930, se ocupó consecutivamente de las revistas Mundo Obrero y Altavoz del frente, órganos de propaganda del Partido Comunista en España al que Falcón acababa de afiliarse. Dado el talante arrojadizo de este periodista que, en su primer viaje a España no vaciló en presentarse en la casa de Pío Baroja, sin más carta de recomendación que su entusiasmo por el autor, no sería de extrañar que Falcón y Chesterton -ambos periodistas beligerantes- se hubiesen conocido en Londres, y que a raíz de este conocimiento fuese el traductor quien propusiera a Cosmópolis la edición de El regreso de D. Quijote. Por estos años la editorial venía publicando títulos de marcada filiación socialista y novelas de subido color. Si aceptó la novela de Chesterton fue, entonces, porque consideraba aceptables sus tesis reformistas. Precedía al texto una dedicatoria de Chesterton a su amigo y colaborador del G.K.'S Weekly, W. R. Titterton, en la cual lamentaba que la guerra y el advenimiento del fascismo hubiesen convertido su parábola de reformadores en una penosa profecía. La historia editorial de la novela de Chesterton fue discreta en las décadas siguientes ${ }^{3}$, y en una de estas ocasiones El monigote de papel, que dirigía José Janés, la incluyó en la serie de clásicos de humor, concretamente en la colección subtitulada "optimista", (una cincuentena de libros de finales de los 40 y principios de los 50 ). Ya sólo esta rúbrica invalidaba y proscribía la teoría

formarían parte del libro de GUILlERMO DE TORRE Las literaturas de vanguardia. En 1919 lanzó un manifiesto de adhesión al modernismo que fue suscrito por insignes escritores españoles y latinoamericanos, entre ellos Borges. Sus páginas difundieron asimismo la poesía de Huidobro y las audacias del movimiento estridentista. En esta editorial salieron los cuentos infantiles de Antoniorrobles, las novelas de Blasco Ibáñez, y abundantes obras de subido color como eran las novelas de Colette y Hoyos y Vinent, además de vidriosos relatos de los decadentistas franceses e ingleses. Entre otros autores, merece destacarse en el catálogo de Cosmópolis a Pedro Mata, Alberto Insúa, Eduardo Zamacois, John Erskine, Emiliano Ramírez Angel, Eduardo Bourdet, Paul Morand, Anita Loos y Mauricio Dekobra. Quizá tuvo que ver la editorial con la Compañía Iberoamericana de Publicaciones (LA CIAP) que, entre 1927 y 1931, intentó revolucionar las estructuras comerciales de la España de aquella época, en la que colaboró Borges, y que fracasó estrepitosamente.

3. César Falcón ha sido el único traductor de esta novela hasta la traducción en 2004 de la novela por José Luis Moreno Ruiz. Su versión se repite en Ediciones de la Gacela, Atlántida, Barcelona, 1942; Ponsa, Barcelona, 1944; Guada, Barcelona, 1958 y 1963. Periodista desde 1910, César Falcón trabajó en La Prensa, La Nación y El Liberal (Lima) junto con José Carlos Mariategui. Fundó El tiempo, periódico de la oposición que sobrevivió de 1916 a 1919, Nuestra época (que sólo conoció dos números) y La Razón, portavoz del movimiento obrero en Lima. En 1920 se trasladó a Madrid y comenzó a trabajar para El Liberal (de Madrid) y La vanguardia de Barcelona. Desde 1923 hasta 1930 fue corresponsal en Londres del diario madrileño $E l$ Sol. A su regreso a España puso en marcha la Central de Ediciones y publicaciones de la que brotaría más adelante la editorial Historia Nueva y ediciones Avance, a las que siguieron Nuestro Pueblo, Jasón, Ulises, Zeus y la CIAP (Cía. Ibero Americana de Publicaciones), éstas últimas en colaboración con otros amigos periodistas. 
política exhibida en la novela del polemista inglés que tanto había interesado a los círculos radicales en España.

Por cierto que otra de las cuestiones debatidas es si un escritor que ejercita la discusión intelectual en el seno de sus novelas, que construye -de alguna manera- novelas de tesis, puede ser tomado en serio por la crítica. Conviene recordar en este sentido lo argumentado por Hilaire Belloc en su ensayo titulado "On the Place of Gilbert Chesterton in English Letters" (1940) donde explica que la tendencia a convertir a Chesterton en un estilista verboso proviene del carácter mortificante de estas obras que exigen al lector un extraordinario esfuerzo de concentración. Chesterton es un escritor que sacude a su auditorio con sus paradojas sorprendentes al mismo tiempo que lo entrena en una cierta destreza filosófica al estimular su pensamiento, destrozar sus rutinas y conmover sus prejuicios, y todo ello en un estilo lúcido, opuesto a la ambigüedad modernista, que sorprende las facetas insólitas de lo real. Arquitecto de la certidumbre lo llamó Belloc, refiriéndose a su implacable argumentación y su capacidad de ilustrar, de dar cuerpo a los hechos mediante el brillante ejercicio del paralelismo y la metáfora. Si algo puede definir el estilo de Chesterton es la palabra "vigor". Por esto mismo, pocas veces ha encontrado Chesterton un traductor adecuado de su obra y más frecuentemente la apariencia de prestidigitador verbal es fruto de la versión un tanto disecada de sus brillantes metáforas.

2. El regreso de D. Quijote culmina una etapa de la obra de Chesterton que la crítica viene llamando periodo quijotesco. Tiene éste su punto de partida en el ensayo titulado La divina parodia de D. Quijote ("The divine parody of D. Quixote", 1901) en que el autor interpreta la novela de Cervantes como una escenificación del combate entre el idealismo y el realismo (el de Sancho Panza) defendiendo la cordura del caballero, corporización del sentido común, contra la locura del mundo que aceptamos por canónico. Poco después, en 1904, Chesterton escribe el Napoleón de Notting Hill, una novela en la que se pormenoriza la contienda entre un humorista y un fanático en la hipotética Inglaterra de 1984. El instinto del juego que mueve a Quinn, el humorista -su apetito de libertad, de elección de lo imaginativo y no reglado- busca quebrantar la ley con el mismo ímpetu con que Wayne, el fanático, representa la opción por el honor del nuevo imperio de Notting Hill. La primera novela de Chesterton sugiere así que existen en el ser humano dos tendencias igualmente imperiosas y mutuamente combativas, la apetencia de lo prohibido, por la que se franquea la puerta a la realización del deseo, y el instinto del cumplimiento de la norma, que restringe la satisfacción del deseo. En términos cervantinos, si el hidalgo Alonso Quijano simboliza la aspiración al ideal del honor su escudero Panza da cuerpo el instinto de la personal satisfacción. La utopía de Napoleón de Notting Hill pone así en escena uno de los tópicos favoritos de Chesterton, también desarrollado en Ortodoxia (Orthodoxy, 1908) y El poeta y los lunáticos (The poet and the lunatics,1929). Si alguien tiene visos de perder la razón es precisamente el 
razonador, el pesimista. Por el contrario, el poeta imaginativo, el soñador, el loco, el que acepta la "razón de la sinrazón que la razón quiera dar" quien descubre la otra espalda de la realidad o mira al mismo tiempo los dos aspectos del problema, quien recibe la paradoja, puede sentirse a salvo en la orilla de la cordura.

Más tarde, en un ensayo de 1911, "The True Romance", Chesterton compara la historia de D. Quijote con la vida de Cervantes y asegura que el novelista español llevó a término la paradoja extraordinaria de escapar de las andanzas caballerescas, en las que se había demostrado el más cumplido héroe, para volver a casa antes que su D. Quijote y mostrar en su gran obra que el ideal de la caballería era imposible. Es lo que Maeztu dice en D. Quijote o el amor (1916). Cervantes, que alguna vez respiró el orgullo del heroísmo caballeresco, con El Quijote quiso marcar el alto, desengañar por su propio bien a los españoles de su tiempo de esas empresas que llevaban camino de arruinar al país y, de hecho, lo arruinaron.Aunque la España del 98 no necesita más desencantos, sino, al contrario, volver a sentir un ideal opina Maeztu.

En 1912 vuelve a aparecer Cervantes en el poema Lepanto, inspirado según afirma Maisie Ward ${ }^{4}$, en las conclusiones de un debate que tuvo lugar en Leeds, en la primavera de 1912, acerca de si todas las guerras europeas no habían sido en realidad guerras de religión. Con motivo de este argumento, el padre O'Connor - con el tiempo sustrato real del personaje de Father Brownhizo una elocuente descripción de la batalla de Lepanto que despertó el entusiasmo de Chesterton. Bajo esta impresión el escritor comenzó el poema y a finales de octubre de ese año pudo publicarlo. La definición que Chesterton da en estos versos de lo que a su juicio es un héroe sirve para entender su creación del arquetipo quijotesco. Entre los grandes salvadores de la humanidad, Ricardo Corazón de León, Raimundo (el conde de Toulouse) y Godofredo (de Boullon) héroes de las Cruzadas, incluye Chesterton a D. Juan de Austria, omnipresente en el escenario de la batalla, invisible en el humo, armado hasta los dientes sobre la cubierta del barco, gritando a las naves y acechando como un cazador que dispara cañones. Según esto el héroe es, y cito por la versión de Jorge Luis Borges, “... aquel que arriesga y que pierde y que se ríe cuando pierde". Por eso, asegura Chesterton, puede decirse que D. Juan de Austria ha sido el último caballero de España, de Europa, porque tomó las armas mientras los Valois bostezaban en misa y la impávida reina de Inglaterra se miraba en el espejo. Él fue el único fervoroso entre legiones de cristianos tibios que nada hicieron por liberar a los suyos, cautivos en las bodegas de las naves turcas. Un hombre al que le importó un ardite el fracaso o el triunfo, el esfuerzo que pudiese costar la empresa. Fue "El último rezagado trovador que oyó el canto del pájaro / Que otrora fue cantando hacia el sur, cuando el mundo entero era joven", un caballero enamorado, valiente, apasionado por su meta. (Sol y Luna, no 1 (1938). Buenos Aires, www.dur.ac.uk). 
Finaliza el poema con la estampa de un hombre, Cervantes, que envaina la espada, y de otro, D. Juan, que regresa a España coronado de laurel. De alguna manera sugiere Chesterton que ha sido el heroísmo de D. Juan lo que inspiró a Cervantes la idea de su Quijote, un caballero flaco e insensato que perdido en los caminos de España cabalga eternamente y en vano. En los versos finales de Lepanto, Cervantes sonríe "pero no como los Sultanes", con una sonrisa de poder y la autocomplacencia. La de Cervantes es una sonrisa de inteligencia, de comprensión. Sabe el escritor cuál es la fuerza y la debilidad de la civilización que se dice cristiana porque es la suya propia. El Quijote es el prototipo del caballero cristiano cuyo honor lo sostiene en las más difíciles pruebas, a diferencia de lo que sucede a Sancho, siempre temeroso de sufrir la más pequeña incomodidad, lo que equivale a asignar al escudero el papel débil y medroso mientras se adscribe a su señor la personalidad fuerte y temeraria. $\mathrm{Y}$ sin embargo, la misma bondad del Quijote lo convierte en fantoche en manos de los despiadados. El mismo impulso a la generosidad del héroe lo transforma en víctima del avasallamiento de otros, tal como sucede en $E l$ regreso de D. Quijote con el bibliotecario Miguel Herne. Sancho y su señor son la misma persona que justifica y representa un ideal. El Quijote es el abanderado de una causa, sea la que fuere, dice Chesterton, que no vacila en calificar a su adversario y amigo, el dramaturgo Bernard Shaw ${ }^{5}$ de quijote del antirromanticismo y romántico quijote del socialismo. El arquetipo quijotesco es el extremo opuesto del donjuanismo, asegura Chesterton, quien ve en el Quijote al hombre honesto por naturaleza, dispuesto a ser perjudicado personalmente con tal de poner a salvo los principios, el primero de ellos la defensa del marginado y del débil. En este sentido es débil D. Quijote, porque rehúsa el pragmatismo, porque renuncia al beneficio propio y a la propia defensa, y es también poderoso e invencible como un Titán cuya gesta principal fuese la paciencia. Y todo porque atisba algo invisible al común de los mortales, porque es un soñador y un visionario de verdades ocultas a los rudos 6 .

El regreso de D. Quijote habla de la locura infecciosa. De aquella que aqueja a un grupo de aficionados ocupados en la preparación de una obra teatral sobre la leyenda de Blondel, el trovador de Ricardo Corazón de León, y que, cumplida la función y liderados por un viejo bibliotecario que ha hecho el papel de rey, se niegan a abandonar sus ropas medievales y deciden instaurar

5. "Mr. Bernard Shaw, a sort of anti-romantic Quixote, who charged chivalry as chivalry charged windmills, with Sidney Webb for his Sancho Panza. In so far as these paladins had a castle to defend, we may say that their castle was the Post Office", en Eugenics and other Evils, cap. VII, "The transformation of socialism" (1917). Vide. www.dur.ac.uk/martin.ward

6. Por lo demás, las alusiones al Quijote, o el empleo del adjetivo quijotesco aplicado a los protagonistas de sus novelas son constantes en toda la producción de Chesterton, como también el perfil contrastante y humorístico de la pareja cervantina en sus muy frecuentes binomios de personajes protagonistas. Es el caso de La hostería volante y del quijotesco propósito del capitán Dalroy de burlar la ley seca ordenada por Lord Ivywood, rebeldía doméstica con la que consigue nada menos que la emancipación del yugo musulmán impuesto a los ingleses. 
en Inglaterra el antiguo orden de la caballería. El periodo quijotesco en el que se inserta esta novela de Chesterton coincide con una etapa especialmente dolorosa en la vida del escritor en la que se mezclan las decepciones políticas ante escándalos como el caso Marconi, las ansiedades de su largo proceso de conversión religiosa, la enfermedad propia y la muerte de su hermano Cecil con el que había compartido tantas aventuras en el pugilato periodístico, singularmente la fundación del New Wittness. El descubrimiento al que ha llegado Chesterton a través de obras como Lo que va mal en el mundo (1910) y la Breve historia de Inglaterra (1917) es que Inglaterra ha sido asesinada, en secreto y hace tiempo, al compás de esa industrialización moderna que ha construido urbes inmensas en las que se hacinan los ciudadanos, progresivamente dominados por la tecnología inhumana. La feliz Inglaterra, el país libre que fue antes de la reforma puritana, yace sojuzgado bajo el control de los grandes financieros y la tiranía de la plutocracia. Lo que plantea pues El regreso de D. Quijote es la restauración de los valores que animaron la sociedad antes de la fundación del estado moderno. Resulta por tanto una novela de significado e intención política y propagandística, una especie de ilustración de lo que de un modo programático buscaba por entonces el distributismo, el movimiento social que Chesterton, Belloc y otros intelectuales ingleses idearon para ofrecer una alternativa al capitalismo y al socialismo marxista. Una alternativa necesaria porque, en su opinión, ambos, capitalismo y socialismo, resultan antidemocráticos. El capitalismo condena a la gran masa de la población al servilismo de unos pocos poderosos que son quienes imponen los ritmos del mercado. Por tanto, en absoluto podría hablarse de democracia en una sociedad en la que la mayoría de los ciudadanos depende de una minoría para su subsistencia. Pero el socialismo no parece menos injusto pues si impide la concentración de capital en unos pocos individuos es para transferir su propiedad al estado, es decir, para construir un tipo de sociedad fundada en la coerción, la servidumbre y la anulación de la libertad. El remedio de la centralización del capital no puede ser otra centralización aunque sea estatal, arguye Chesterton. Lo que consigue secundariamente la lucha del socialismo contra el capitalismo es la restricción de las libertades y la sujeción del individuo al proteccionismo de nuevos oligarcas. De ahí la desconfianza de Chesterton hacia los líderes sindicales, tal como ejemplifica en su novela a través del personaje de Braintree, un sindicalista que jamás ha visitado una taberna de barrio y que no sabe manejarse con la clase baja a la que defiende. El distributismo, por el contrario, va a proponer no ya la igualdad de condiciones sino de oportunidades y para ello el reparto equitativo de la propiedad por la constitución de una sociedad de pequeños empresarios que sean capaces de autoabastecerse, garantizada por ciertas leyes que impidan la concentración del capital. Es justo, defiende Mr. Herne, protagonista de El regreso de D. Quijote, que quien desarrolla un oficio sea propietario de los medios de producción. Es necesario además para el ser humano contar con un pequeño ámbito de actuación que le sea propio, donde él pueda expresar su personalidad y su iniciativa. Por esto el distributismo no sólo denuncia el enriquecimiento inmoral de los 
grandes señores sino también la estandarización de la sociedad a que estaba empujando el desarrollo tecnológico. Por eso, en el momento de la fundación de la Liga distributista -dos meses antes de terminarse la publicación de $E l$ regreso de D. Quijote, el 17 de septiembre de 1926- se barajó entre otros nombres para bautizar al movimiento el de la Liga de los luditas. Chesterton fue el presidente de esta sociedad en la que participaron antiguos socialistas fabianos como A. R. Orage, director y fundador de la revista The New Age, o el arquitecto A. J. Penty (que en 1906 había publicado un libro sobre la restauración de los gremios medievales) antiguo colaborador de William Morrison y John Ruskin. Estaban además Maurice Reckitt, el padre Vincent Mc Nabb, Sir Henry Slesser, y W. R. Titterton todos ellos relacionados de algún modo con los cristianos socialistas, bien como católicos o anglocatólicos. El órgano portavoz del movimiento fue el G.K's Weekly, el periódico donde salía por entonces El regreso de D. Quijote, y entre los triunfos de la liga merece recuerdo la recogida de casi un millón de firmas de ciudadanos contra el monopolio de la empresa municipal de transportes y su participación conjunta con los laboristas en la huelga general de 1926. Como es evidente, algunos episodios de la novela de Chesterton siguen a la letra acontecimientos de la política inglesa del momento, concretamente el de la huelga de los trabajadores del carbón promovida por Braintree y las elecciones generales. Y desde esta perspectiva cobran nuevos significados también algunos incidentes del relato como la visita que Murrel hace a los grandes almacenes para comprar un antiguo pigmento en desuso, un episodio que el personaje convierte en toda una epopeya caballeresca y en una especie de novela policíaca también. Este capítulo -materia intercalada como en el Quijote y aparentemente sin relación con el argumento principal- es de sumo interés para la resolución de la trama pues muestra las consecuencias de la producción en serie y el maquinismo. Pero hablando del distributismo, concluirá Chesterton en $\mathrm{El}$ delineamiento de la cordura (The Outline of Sanity, 1927): "Dicen que es utopía y están en lo cierto. Dicen que es idealismo y están en lo cierto. Dicen que es quijotismo y están en lo cierto. Cada uno de estos nombres indica de modo correcto que la justicia ha sido arrojada del mundo"7. Por eso, como desfacedor que es de agravios y restaurador de la justicia D. Quijote se convierte en el abanderado del distributismo en esta novela de Chesterton y su discurso de la Edad Dorada, proclamado durante el juicio contra Braintree, incluye todos los puntos sustanciales de una doctrina que trataba de combinar el socialismo fabiano, el activismo sindicalista, las iniciativas del Guild Socialism y la Rerum Novarum. El mismo argumento recorre las páginas de La crisis del humanismo, redactada en inglés por Ramiro de Maeztu en 1919, quien, por cierto, había colaborado con Chesterton y Belloc en las páginas de la revista The New Age.

7. The Outline of Sanity, "On a Sense of Proportion", Colección de escritores ingleses, Bernard Tauchnitz, Leipzig, sa., p. 156. 
Si entendemos el quijotismo como obsesión, locura, manía, son varios los personajes quijotescos en El regreso de D. Quijote. En primer lugar el bibliotecario Mr. Herne, apasionado de los estudios históricos sobre la civilización hitita y después fanático del espíritu del medioevo, cuyo retrato coincide significativamente con el del personaje cervantino y con la acuñación iconográfica de la novela.

El bibliotecario era ciertamente de esa clase de gente remisa a la luz del día y era una sombra entre las obras sombras de la biblioteca. Su figura era larga y derecha, pero habitualmente llevaba un hombro más alto que el otro. $\mathrm{Su}$ pelo era de un rubio polvoriento. Su cara era flaca y sus facciones largas y rectas; pero sus ojos azules estaban un poco más separados uno del otro que los de la demás gente, haciendo el efecto de que le faltaba un ojo. Era verdaderamente un efecto raro, como si su ojo estuviera en otra cabe$\mathrm{za}^{8}$.

Parece bastante lógico que la biblioteca sea el lugar donde pueda encontrarse a un quijote, por definición un hombre anclado en la ensoñación del pasado glorioso que busca resucitar. La selección de imágenes en los quijotes ilustrados lo confirma numerosas veces. El bibliotecario de la abadía de Seawood ha vivido luengos años oculto en esa cueva del saber, absorto en sus meditaciones históricas, y ocupado en las intensas aventuras y los espejismos que le sugiere la reconstrucción del pasado. Cuando decida pasar la noche en claro en lo alto de una escalera devorando infolios sobre la era medieval se aplicará a la reconstrucción de la sociedad caballeresca con la misma fiereza y pasión. Al final de la novela, exiliado del breve reino medieval que ha fabricado, sube al caballo del viejo simón, lanza en ristre, reproduciendo la estampa que Doré y otros ilustradores habían convertido en prototípica.

Los huesos de la flaca faz de facciones duras, la apuntada barba como una llama, los ojos hundidos y exaltados, formaban un cuadro preñado de vocaciones. Rígido sobre la silla de Rocinante, algo y cubierto de vetusta armadura, levantó aquella inútil lanza que durante trescientos años nos ha enseñado a reírnos del acto de enristrarla. Y detrás de él se erguía una inmensa sombra parecida a la visión misma de aquel leviatán de la risa; el grotesco coche, como las mandíbulas de un dragón irrisorio, persiguiéndole eternamente, como la enorme sombra de la caricatura persigue a nuestra desesperada dignidad y belleza, siempre pendiendo amenazadora sobre ellas, como la ola del mundo; y, sobre todo, el ágil y ligero espíritu humano mirando hacia abajo, no con crueldad, a todo lo que es más alto. (ibid. 287)

8. G.K. Chesterton, El regreso de D. Quijote, Madrid, Cosmópolis, s.a., pp. 32-33. 
Como arquetipo quijotesco puede contarse también a Olive, la autora de Blondel, el trovador, ensimismada en sus pretensiones estéticas y Julián Archer, el hombre de moda, pronto a subirse al carro del medievalismo para no perder la oportunidad de dirigirlo. $\mathrm{Y}$ al sindicalista, Braintree, fanático de la reforma social aunque también un hombre honrado, y a la hija de Lord Seawood, Rosamund, la más ferviente de los partidarios de Herne. Pero sólo el fracasado y juguetón Murrell, que se autodenomina Sancho Panza, es el Otro, el verdadero Quijote, asegura Mr. Herne al final de la novela. Y esto porque Murrell ha sido el salvador de un loco, el Dr. Hendry, que abstraído en el pasado, empestillado en su teoría de la ceguera cromática, no cesa de asegurar que "cualquiera que diga que las pinturas que se anuncian en esas hojas volantes son mejores que las mías debe ser un loco. Y así, en cierto sentido, la mayor parte de la gente está realmente loca. En lo que los científicos de la época han fracasado completamente es en investigar por qué están locos" (ibid. 128). Sólo la locura de la sociedad moderna puede hacer preferibles los productos industriales a los hermosos objetos del artesano de antaño. Por esta acción, el nuevo rey de Armas, Mr. Herne, concede a Murrell el escudo de honor: por haber sido el único hombre en estos tiempos de malandrines, que "ha hecho la única hazaña digna de hacerse en estos días, que ha vengado la mala acción de un bribón, por lo menos, y que ha salvado a una mujer necesitada" (ibid. 234). Y reabundando en el tema conviene recordar que en 1901 Chesterton había defendido la novela de detectives alegando que estos relatos constituían el moderno romance de caballería (A defense of Detective Stories). El policía y el detective son los modernos caballeros errantes que protegen a la sociedad del desorden repite El hombre que fue jueves (The Man Who was Thursday, 1922). En El regreso de D. Quijote cada uno de estos personajes representa además una actitud diferente hacia el pasado, concretamente hacia los llamados siglos oscuros e inhumanos que, como probará Chesterton, fueron más libres y humanos que los nuestros. Esta es la primera evidencia que deja ver la novela, la identificación de quijotismo y medievalismo, asociación que no deja de sorprender. Para Chesterton, el Quijote no es tanto una parodia de las novelas de caballería como la resurrección de este espíritu en mitad del Renacimiento europeo. O dicho de otro modo, Cervantes, comprendió verdaderamente su época, lo qué significaba renacer, resucitar, recuperar el pasado. Por eso Chesterton planta a su Quijote en la representación de una obra teatral en la que se dan cita los personajes legendarios de los viejos romances de caballería, Ricardo, Arturo, Lancelot. El espíritu de la caballería es el de la justicia y la nobleza, una época genuina, explica el bibliotecario Herne a sus súbditos, una sociedad que desdeñó la impostura y el eufemismo. En la leyenda de Ricardo, "Juan es el traidor; Juan es el tirano; Juan es el criminal universal", el enemigo no se oculta (Herne habla de Juan Braintree, el sindicalista, y de Juan sin tierra), es más humano, identificable. Pero nunca en los tiempos antiguos se habría llegado a la crueldad que revela el caso de Hendry en que la ciencia, dura, objetiva, lógica y económica, ha intentado separar a este pobre viejo de todo lo que ama -en primer lugar su hija- bajo el pretexto de que es 
un loco. Si Herne promueve el regreso al medioevo, por otra parte el periodo histórico más frecuentado en las novelas de Chesterton, es para volver al contacto con lo natural y genuino, para restaurar el valor perdido de la democracia la cual sólo se aclimata en una comunidad capaz de reconocer sus errores. Desde luego, no conducen a ella los derroteros de la sociedad moderna con el maquinismo, el libre comercio, el capitalismo, la plutocracia. No hace falta decir que esta visión está impregnada de un romanticismo tan insostenible como el sentimentalismo estético un tanto prerrafaelita que mueve a Olive Ashley a recrear un drama histórico, el tradicionalismo de Archer y Rosamund o el oportunismo de Lord Seawood para dirigir en beneficio propio la devoción popular por el pasado. Lo que sí parece claro es que cada personaje simboliza en esta novela una actitud distinta hacia el pasado y que el portavoz del propio Chesterton es, indudablemente, el burlón Murrell.

Por eso Chesterton, en una pirueta característica de sus relatos termina convirtiendo a Braintree en el prototipo de hombre del medioevo cuando en el proceso contra él el código del derecho medieval acaba apoyando su causa. Y permite que sea sólo Murrell, cuando todos aprueban el éxito de Herne, quien comprenda que es un error dejar en manos de un loco el destino de un país. Lo último que Inglaterra quiere es ser gobernada por un hombre fuerte, un hombre de estado, un caballero, pues la esencia de la aristocracia inglesa consiste en el gobierno comunitario. Quien se convierte en héroe de algunos, necesariamente se transforma en el tirano que otros buscan derrocar. Braintree no debería haber llegado al tribunal, afirma Murrell, porque con él se ha hecho el proceso al liberalismo, se ha aplastado la posibilidad de la rebeldía y la gran oportunidad de la democracia. Y Murrel se define a sí mismo como el último liberal, o más bien, como un gran viejo que ha visto muchas cosas. Pero está claro, afirma Chesterton en la novela, que si las decisiones del loco al que los cuerdos nombraron rey llegan a molestar a los poderosos, entonces los poderosos lo acusarán de lunático y lo arrojarán del trono. Es lo que sucede a Herne tras el juicio de Braintree, cuando han sido desenmascarados los falsos aristócratas. Sin embargo el caballero renunciará tranquilamente al trono porque nunca ha olvidado cuál era su misión desde que ocupó el cargo, "Si ceso de ser rey o juezgrita- siempre seré, sin embargo, un caballero, aunque sea, como en la función un caballero errante". Así pues, el Quijote es ese hombre al que la codicia y las motivaciones económicas no han logrado corromper. Con la lanza en ristre se dirige hacia las puertas del parque. Tras él corre Murrell. Herne le pregunta “¿Para qué quiere venir conmigo?” -y Murrel contesta: “¿No me conoce usted?", "¿No sabe usted mi nombre? Bueno, es posible que no conozca usted mi verdadero nombre. (....) Mi nombre es Sancho Panza" (ibid. 286).

Lo grotesco siempre persigue las huellas de lo fantástico, y grotesco es el cortejo que se pone en marcha hacia el exilio "Tal vez algún día se contará la historia del nuevo Don Quijote y del nuevo Sancho Panza y sus andanzas por los caminos de Inglaterra", concluye Chesterton. Desde el punto de vista del satírico populacho fue la historia de dos locos que conducían un viejo coche de caballos, un método nuevo de viaje en los anales de la caballería. 
Pero algún tumultuosamente romántico cronista puede dar sin embargo, una versión de cómo ellos intentaron utilizar el vehículo de varias maneras para defensa y consolación de los oprimidos. De cómo recogieron a los peatones y pasearon a los niños; de cómo en Reading convirtieron el coche en un café y en una tienda en la Salisbury Plain; de cómo el coche figuró como una bañera en el horrible asunto de Worthing; de cómo los simples calvinistas del Border lo tomaron por púlpito errante, con su sitio abajo para que el chantre cantara y un sitio arriba para que predicara el ministro, cosa que Mr. Douglas Murrel hizo con gran unción y edificación; de cómo Mr. Murrel organizó una serie de conferencias históricas por Mr. Herne, pronunciadas desde lo alto del coche y secundadas con comentarios y explicaciones, logrando un gran éxito financiero por métodos tal vez no invariablemente respetuosos del conferencista (ibid. 300).

$\mathrm{Y}$ en las charlas de caballero y escudero resuena la pregunta de Chesterton, ¿regresará otra vez D. Quijote? ¿Nacerá como caballero errante? La razón está muriendo afirma Mr. Herne y su vejez no es más respetable que la del romance parodiado por Cervantes. El error del Quijote no fue tanto atacar a los molinos como no haber luchado contra los molineros, primeros mesócratas de la vida moderna; porque sus molinos "fueron el principio de todos los molinos y factorías que han oscurecido y degradado la vida moderna", asegura Herne. Y este no fue el único error del héroe. "Don Quijote libertó a un grupo de cautivos que sólo eran convictos. En nuestros días es más frecuente que aquellos que han sido arruinados estén en prisión y que aquellos que los han robado estén libres" (ibid. 301). El caballero cabalga una vez más por el bosque, dice Herne. Sólo que ahora no yerra entre los árboles sino entre las ruedas de los automóviles. Se ha creado un sistema de muerte, inhumano, natural a fuerza de cruel, tan aceptado y tan inmenso que no podemos conocer cómo ni dónde actúa.

Esta es la paradoja. Las cosas se han hecho incalculables a fuerza de ser calculadas. Han atado a los hombres a herramientas tan gigantescas que ellos no saben sobre quién caen los golpes. Han justificado la pesadilla de Don Quijote. Los molinos son realmente gigantes. (ibid. 302)

Para concluir la novela, Chesterton permite a su pareja protagonista que al fin reconozcan en lo hondo del corazón la llamada de la ternura y después de un cierto tiempo de peregrinar, amo y criado se animan mutuamente a volver en pos de sus amadas. Herne regresa a la abadía de Seawood y Murrel continúa su camino hasta la casa de Hendry. La abadía ha recuperado su antigua identidad, es decir, ha dejado de ser la residencia ufana de un noble para regresar a su antiguo uso religioso. Rosamund Saverne, una vez desvelado que su título es postizo, ha recuperado su verdadero y plebeyo apellido y ahora se nombra a sí misma Miss Smith. En la pared de una calle, iluminada por un 
farol, una imagen de S. Francisco orlada por un ángel rojo, señala el lugar de la nueva residencia de la mujer. El rojo ha sido el símbolo de la fantasía y del ideal a lo largo de la novela y ha brillado en las miniaturas de los códices, en la corbata de Braintree, en el telón de las decoraciones de teatro, en el incendio de la huelga, en el pelo de Rosamund y en el extraordinario sabor del vino rojo que supuestamente configura el blasón de la nariz roja, asevera el bromista Murrell. "En el universo material, el rojo es lo más alegre y lo más terrible", dice Chesterton en Alarmas y digresiones ${ }^{9}$ (Alarms and Discusions, 1910) El final de la novela revela a Olive que el rojo deseado, el tono que buscaba para sus pinturas, estaba en esa corbata de Braintree; esto es, que los contrarios no se oponen, que la paradoja es necesaria, la paradoja de rescatar de los extremos más opuestos la brizna de justicia que pueda subsistir. La sonrisa del grave Herne al final de la novela es el hecho insólito de la cordura. Toda la peripecia de la novela ha partido de aquí, de la búsqueda del pigmento para la pintura del ángel rojo del decorado teatral. Y es posible que la contradicción sólo sea aparente, explica Chesterton en Enormes minucias (1909). "Tal vez no habéis nunca oído hablar de un ángel rojo. Pero habéis oído hablar de un diablo azul. Eso es exactamente lo que quiero decir"10.

\section{BIBLIOGRAFÍA}

AmIS, K., (1973), "Four Fluent Fellows", Encounter, Oct.: 94-100.

ACCARDo,P., (1992) "The Puppet Show of Memory: Chesterton, Calderón and Cervantes", The Chesterton Review, August (18) 3: 395-304.

CoAtes, J., (1980), "The Restoration of the Past and the War of Values: The Image of D. Quixote in Chesterton Work", The Chesterton Review (Spring-Summer) 6: 280-304.

ChesterTON G.K., (1967), Obras completas, Madrid, Plaza.

Chesterton G.K., (1927), El regreso de D. Quijote, Madrid, Cosmópolis.

Deleuze, G., Guattari, F., (1990) Kafka: por una literatura menor. México, Ediciones Era.

MedCalF, S..(1987) "Fresh, Capacious and upside down", Times Literary Suplement, Dec.: 1419-1420.

WhiteHoRn, K., (1974), “The return of G.K. Chesterton”, Observer, Sept: 20-23.

9. Chesterton G.K., (1967), Obras completas, vol. I, Madrid, Plaza., p. 979.

10. Obras completas, vol. I, p. 1352.

ANALES CERVANTINOS, VOL. XXXVII, PP. 239-252, 2005. ISSN: 0569-9878 


\section{Resumen}

El regreso de D. Quijote (The Return of D. Quixote, 1926) culmina una etapa de la obra de Chesterton que la crítica viene llamando periodo quijotesco. Tiene ésta su punto de partida en el ensayo titulado La divina parodia de D. Quijote (The divine parody of D. Quixote, 1901) en que el autor interpreta la novela de Cervantes como una escenificación del combate entre el idealismo y el realismo (el de Sancho Panza) defendiendo la cordura del caballero, corporización del sentido común, contra la locura del mundo que aceptamos por canónico. La misma contradicción había encontrado un sagaz análisis en la novela utópica de 1904 The Napoleón of Notting Hill y continúa explorándose en varias obras fundamentales como el poema titulado Lepanto de 1912. Pero es la entrega de la Weekly's Review cuando D. Quijote se convierte en adalid de la causa distributista y el retorno a una sociedad medievalizante en símbolo no sólo de la recuperación de las virtudes caballerescas sino también de su prototipo inspirador, la utopía de una sociedad cristiana.

Palabras clave: Chesterton, influencia, idealismo, realismo, locura, utopía.

\section{Summary}

The Return of D. Quixote, 1926, consummates a stage in Chesterton's life that the critics have called the quixotic period. The departing point for this time period was an essay called The divine parody of D. Quixote (1901) in which the author interprets Cervantes' novel as a performance of the combat between idealism and realism. Sancho Panza portrays the image of the knight embodying common sense and opposed to certain madness that we have come to consider as normal in the world we live. This paradox had been already subject of a witty analysis in the utopian novel The Napoleon of Notting Hill of 1904. It is also explored in other relevant works like the poem entitled Lepanto of 1912. It is only in the Weekly's Review issues where D. Quixote becomes the advocate of the distributionist cause and the return to a medieval society as a symbol of the revival of the knight's virtuousness and of its inspiring prototype, the utopia of a Christian society.

Key works: Chesterton, influence, idealism, realism, madness, utopia. 